\title{
Contralateral osteotomy of the pedicle and posterolateral elements for en bloc resection: a technique for oncological resection of posterolateral spinal tumors
}

\author{
Viren S. Vasudeva, MD, ${ }^{1}$ Alexander E. Ropper, MD, ${ }^{2}$ Samuel Rodriguez, MD, ${ }^{3}$ Kyle C. Wu, MD, ${ }^{1}$ and \\ John H. Chi, MD, MPH'1,4 \\ ${ }^{1}$ Department of Neurosurgery, Brigham and Women's Hospital, Harvard Medical School, Boston, Massachusetts; ${ }^{2}$ Department \\ of Neurosurgery, Baylor College of Medicine, Houston, Texas; ${ }^{3}$ Department of Anesthesiology, Perioperative and Pain Medicine, \\ Stanford University School of Medicine, Stanford, California; and ${ }^{4}$ Center for Neuro-Oncology, Dana-Farber Cancer Institute, \\ Boston, Massachusetts
}

En bloc resection of tumors involving the spinal column is technically challenging and is associated with high morbidity to the patient due to the proximity of critical neurological and vascular structures and the destabilizing nature of this surgery. Nevertheless, evidence has shown improved progression-free survival with en bloc resection for certain low-grade malignant and aggressive benign musculoskeletal tumors. To avoid the morbidity of en bloc spondylectomy in patients with tumors localized to the lateral and posterolateral spinal column, the authors have found that the goals of surgery can be accomplished through a contralateral osteotomy of the pedicle and posterolateral elements for en bloc resection (COPPER). They reviewed their series of 5 patients who underwent successful tumor removal through a COPPER approach. These patients were all found to harbor spinal column tumors involving the posterolateral elements that, based on pathology, would benefit from en bloc resection. Tumor pathology included chondrosarcoma, leiomyosarcoma, osteoblastoma, and liposarcoma. Resections were performed by completing ipsilateral facetectomies above and below the lesion and ipsilateral pedicle osteotomies from a contralateral approach following hemilaminectomy. By disarticulating the posterolateral elements while carefully protecting the thecal sac, the tumors were removed en bloc along with the affected lamina, pedicles, pars interarticularis, and spinous processes, allowing tumor-free margins. This technical report suggests that the COPPER approach is safe and effective for en bloc resection of tumors involving the posterolateral aspect of the spinal column with tumor-free margins and that it eliminates the need for anterior column reconstruction. https://thejns.org/doi/abs/10.3171/2016.8.SPINE16398

KEY WORDS spinal tumor; en bloc resection; spinal osteotomy; COPPER; oncology; surgical technique

$\mathrm{E}$ N BLOC resection is defined as an attempt to remove a tumor in one piece. In the spinal column, this poses a formidable surgical challenge. Critical neural and vascular structures are encased within the spinal column, making radical en bloc excision of the tumor and entire compartment of origin impossible in most instances. Instead, the goal for most spine surgeons is to achieve a marginal en bloc resection of tumors entering the spinal canal or a wide en bloc resection of tumors that lie adjacent to the spinal column and may involve the bone but do not have epidural extension. Despite the high morbidity associated with these operations, many surgeons choose to perform aggressive resections, such as the total en bloc spondylectomy described by Tomita et al., as this has been shown to improve progression-free survival for many pathologies. ${ }^{18}$

However, we have found that for posterolaterally located tumors, a less aggressive approach can be taken to achieve the goal of en bloc resection. The contralateral osteotomy of the pedicle and posterolateral elements for en bloc resection (COPPER) procedure, which we describe in this paper, is an effective technique to remove tumors involving the posterior elements, facet joints, or pedicles in an en bloc fashion with wide surgical margins while reducing the challenges and risk associated with such surgery.

The technical note and illustrative cases that follow show the versatility of the COPPER procedure for these specific lateralized tumors and suggest that this technique is a safe and effective method for en bloc resection of spinal tumors in appropriately selected patients.

\section{Methods}

Patients who underwent en bloc resection of spinal tumors using the COPPER technique at the Brigham and 
Women's Hospital/Dana-Farber Cancer Institute were identified, and their medical records were reviewed. Data collected included age at the time of surgery, sex, pathology, operative technique, operating time, blood loss, complications, and local recurrence, as well as the patients' current clinical status. The extent of resection was classified as either wide en bloc or marginal en bloc based on operative reports, imaging studies, and surgical pathology. Wide en bloc resections were performed when a layer of healthy tissue fully surrounded the tumor and could be removed together with the tumor in one piece. Marginal en bloc resections were those in which the tumor and tumor capsule were removed in one piece, but a layer of surrounding healthy tissue was not present. ${ }^{4,5}$

\section{Patient Selection and Counseling}

Prior to surgery, patients underwent MRI with and without gadolinium contrast and high-resolution CT scanning of the spine. These studies were designed to include the entire tumor as well as several vertebrae above and below, which were used for reconstruction. Because we suspected that these lesions were primary malignant spinal column tumors or some other musculoskeletal tumor that might benefit from en bloc resection, we performed percutaneous CT-guided biopsies with a sheathed needle using a tract that could later be resected at the time of surgery. After the tissue diagnosis was confirmed to be consistent with a lesion that should be resected in an en bloc fashion, a plan was made to perform the resection using the COPPER technique. We only considered using this procedure for lateral or posterolateral paraspinal tumors located between C-7 and L-5. Using the Weinstein-Boriani-Biagini surgical staging system, we found these tumors located in either sectors $1-4$ or $9-12.5$ This procedure cannot be performed bilaterally and was not considered for lesions in the cervical spine above the entrance of the vertebral arteries or for sacral lesions. If nerve roots with motor function were to be ligated during surgery, patients were counseled on the expected postoperative neurological deficits.

\section{Technical Description of the COPPER Procedure}

Patients were placed under general anesthesia and positioned prone on an open Jackson table. Intraoperative neuromonitoring with motor evoked potentials, somatosensory evoked potentials, and spontaneous electromyography was used in most cases. A midline linear incision was made that spanned the entire length of the tumor, and a subperiosteal exposure was performed along the base of the contralateral spinous processes and laminae. Above and below the level of the tumor, a bilateral subperiosteal exposure was then performed.

Prior to beginning the bony resection, the tumor and tumor capsule were dissected free from surrounding soft tissue with generous surgical margins. Sometimes this might require a lateral extracavitary, transthoracic, retroperitoneal, thoracoabdominal, or other approach, which can be performed initially as a first-stage surgery. In our experience, it has been useful to involve a multidisciplinary team of thoracic, vascular, and oncological surgeons for staged operations. The steps of the procedure are as follows.
Step 1

Complete laminectomies above and below the tumor were performed to expose the dura. A contralateral hemilaminectomy was then performed, connecting the rostral and caudal laminectomies while preserving the midline spinous processes and ligaments. The laminectomy was wide enough that the contralateral pedicles could be identified when looking obliquely over the dorsal thecal sac (Fig. 1).

\section{Step 2}

The ipsilateral pars interarticularis and facet joints were resected above and below the tumor to prepare for the posterior release (Fig. 2).

\section{Step 3}

Using an oblique angle over the thecal sac, the pedicles and nerve roots ipsilateral to the tumor were exposed and identified. Given the very limited view, care was taken not to compress the thecal sac, and intraoperative neuromonitoring signals were carefully monitored. The exiting nerve roots were cauterized and ligated when appropriate, improving exposure of the pedicles ipsilateral to the tumor. A contralateral approach was taken to perform an osteotomy of the pedicle ipsilateral to the tumor using either a drill or osteotome. The pedicle osteotomy was placed as close as possible to the base of the pedicle (Fig. 3).

If necessary, to achieve adequate margins, a portion of the lateral vertebral body was removed by increasing the angulation of the osteotomy. If a portion of the vertebral body was removed, it was also necessary to perform proximal and distal partial discectomies. The preoperative images were reviewed carefully to ensure that no major vascular structures were disrupted if the anterolateral cortex of the vertebral body was violated during this osteotomy.

Once the pedicle osteotomies were complete, the facet joints rostral and caudal to the lesion were resected, the nerve roots were ligated, and tumor was dissected free from surrounding soft tissue with adequate margins, the specimens were mobile and could be removed en bloc.

\section{Results}

Five patients were identified who underwent en bloc resection of posterolateral spinal tumors using the COPPER technique. All surgeries were performed by the senior author (J.H.C.). Two patients were female and 3 were male. The mean age at the time of surgery was 43.8 years (range 23-62 years). All patients underwent percutaneous biopsy prior to surgery; final surgical pathology included chondrosarcoma, osteoblastoma, metastatic myxoid liposarcoma, and metastatic leiomyosarcoma. In both patients with metastatic lesions, the spinal tumor was the only site of disease. In 1 patient the pedicle osteotomy was performed in the cervical spine, in 3 patients osteotomies were performed in the thoracic spine, and in the remaining patient osteotomies were performed at the thoracolumbar junction. The mean operative time was 460 minutes (range 232-776 minutes) and the mean estimated blood loss was $1670 \mathrm{ml}$ (range 200-7000 ml). En bloc resection was pos- 


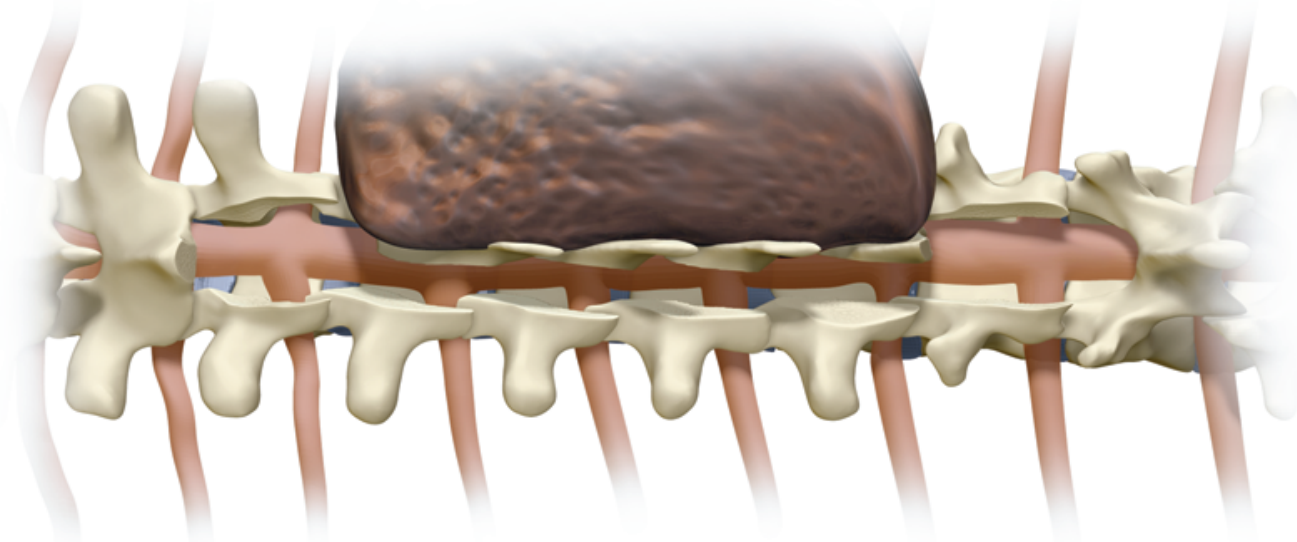

FIG. 1. Step 1. A contralateral hemilaminectomy is performed at the level of the tumor, and complete laminectomies are performed cranial and caudal to the tumor. Copyright Samuel Rodriguez. Published with permission.

sible in all cases, and the extent of resection was classified as wide en bloc for 1 patient and marginal en bloc for the remaining 4 patients. There were no intraoperative complications; however, 1 patient developed hardware failure related to avascular necrosis of the surrounding bone due to high-dose adjuvant radiation therapy. One patient with metastatic leiomyosarcoma developed lung metastases 2 months after surgery; however, the remaining 4 patients did not experience recurrence of disease with an average follow-up of 30.5 months. None of the patients experienced local recurrence, and there have been no deaths in this series (Table 1).

\section{Illustrative Cases}

\section{Case 1}

A 37-year-old man presented with intermittent back pain and a firm, slowly enlarging mass over his right lower back. MRI revealed a large, irregularly shaped, heterogeneously $\mathrm{T} 2$ bright right-sided paraspinal mass that measured $16.8 \mathrm{~cm}$ in craniocaudal dimension and $7.1 \times 8.6 \mathrm{~cm}$ in maximal axial dimension extending from T-1 to L-3 with extension into the neural foramina at L-1 and into the psoas and retroperitoneal space. A CT scan demonstrated that the lesion was diffusely calcified (Fig. 4). A percuta- neous biopsy was performed, and the findings were consistent with chondrosarcoma.

Surgery for en bloc resection was performed in 2 stages in the same session of anesthesia. First, with the patient in the left lateral decubitus position, a right retroperitoneal approach was performed to release the tumor anteriorly and laterally from the surrounding soft tissue. The right kidney was reflected anteriorly during the approach, and the psoas muscle was identified and divided superiorly, taking care to preserve the L-2 nerve root. The proximal portion of the psoas muscle was dissected free from the spinal column, leaving it connected only to the overlying tumor. Laparotomy sponges were placed in the retroperitoneum between the right kidney and the psoas muscle, so that this plane could be more easily identified during the posterior approach. The retroperitoneal incision was then closed and the patient was turned prone on an open Jackson table for the posterior portion of the surgery.

An incision was made slightly left of midline from T-9 to L-4, and the COPPER procedure was performed as described above for en bloc removal of the tumor. A left-sided subperiosteal exposure was performed from T-12 to L-2, and a bilateral exposure was performed above and below at T-11 and L-3. The muscular fascia overlying the tumor was kept intact, and a subcutaneous dissection

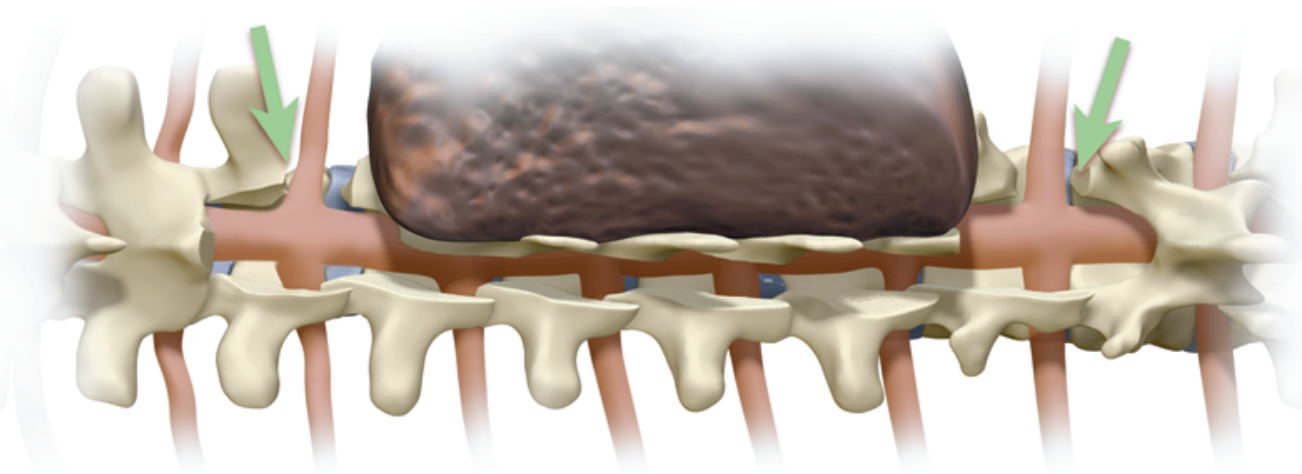

FIG. 2. Step 2. Total facetectomy and resection of the pars interarticularis above and below the tumor (arrows) are performed in preparation for posterior release. Copyright Samuel Rodriguez. Published with permission. 


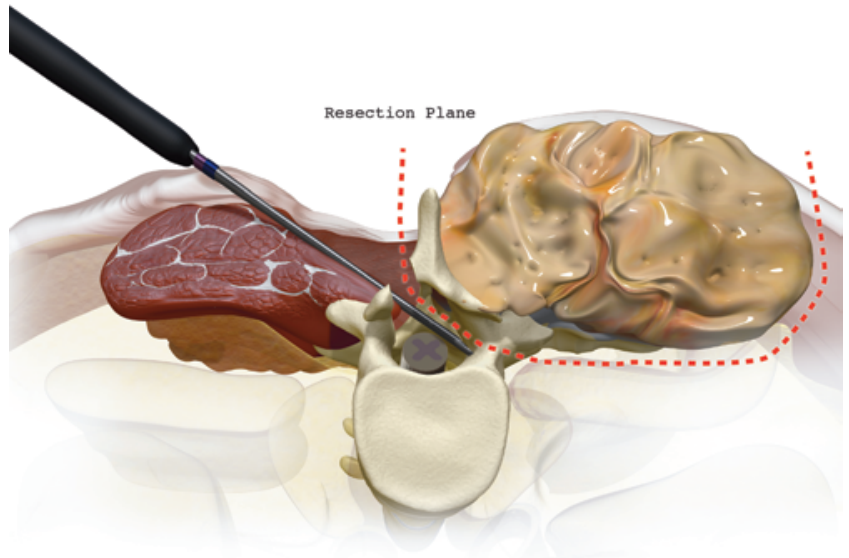

FIG. 3. Step 3. A contralateral approach is taken to perform an osteotomy of the pedicle ipsilateral to the tumor via an oblique angle above the thecal sac using an osteotome. Copyright Samuel Rodriguez. Published with permission.

was performed using electrocautery over the dome of the tumor from the superior to inferior pole. Laminectomies and right-sided facetectomies were performed at T11-12 and L2-3, and a continuous left hemilaminectomy was performed from $\mathrm{T}-12$ to $\mathrm{L}-2$, exposing the spinal dura. The spinous processes were then undercut using a highspeed drill and Kerrison rongeur so that the contralateral pedicles and nerve roots could be clearly visualized at an oblique angle over the thecal sac. Contralateral pedicle osteotomies of T-12, L-1, and L-2 were then carried out using an osteotome. The T-12 and L-1 nerve roots were ligated, and the L-2 nerve root was preserved. The tumor specimen, which was now disarticulated, became mobile and was released from the remaining residual soft-tissue attachments along the spine, allowing it to be removed in one piece (Fig. 5). The right kidney and Gerota's fascia were seen protruding through a posterior hernia into the resection cavity (Fig. 6). Inspection of the mass confirmed that it was removed en bloc with an intact tumor capsule within (Video 1).
VIDEO 1. Case 1. Video of a large Grade II chondrosarcoma that was removed en bloc using the COPPER technique. This specimen is the same one pictured in Fig. 5. Copyright John Chi. Published with permission. Click here to view.

Frozen pathological specimens from the margins of the resection underwent examination, which confirmed a lack of residual tumor in the cavity. The posterior hernia was then closed using a porcine-skin derived surgical mesh with the assistance of a plastic surgeon.

A posterolateral instrumented fusion was then performed from T-10 to L-3. Rods were secured, and the wound was closed in a layered fashion with multiple drains. Pathological examination confirmed that the tumor was a Grade II chondrosarcoma arising from the 12th rib with negative margins. The patient recovered very well with some mild right leg weakness that resolved, and postoperative imaging confirmed complete resection of the tumor. Given the tumor pathology, the patient did not undergo any adjuvant treatment and has been monitored closely for 30 months following surgery with no evidence of disease.

\section{Case 2}

A 23-year-old man with a long history of neck pain presented with a several-month history of sensory changes in his legs and across his abdomen. MRI and subsequent CT scanning of the cervical and thoracic spine demonstrated an expansile mass at C-7 that primarily involved the lamina and pedicle on the right side with epidural extension and leftward displacement of the spinal cord (Fig. 7). A needle biopsy was performed but yielded nondiagnostic results. However, because imaging characteristics were concerning for a primary vertebral body tumor, en bloc resection of the lesion was planned.

The patient was positioned prone in a Mayfield head holder. A midline incision was made from C-5 to T-2, and a bilateral subperiosteal exposure was performed from C-5 to T-2, leaving a small amount of muscle over the left spinous process, lamina, and lateral mass of C-7. Lateral mass and pedicle screws were placed at C-5, C-6, T-1, and T-2. Following this, the laminae of C-6 and T-1 were removed and an osteotomy was performed at the junction

TABLE 1. Patient demographics and clinical data

\begin{tabular}{|c|c|c|c|c|c|c|c|c|c|c|c|}
\hline $\begin{array}{l}\text { Case } \\
\text { No. }\end{array}$ & $\begin{array}{l}\text { Age } \\
\text { (yrs), } \\
\text { Sex }\end{array}$ & Pathology & $\begin{array}{l}\text { Osteotomy } \\
\text { Level(s) }\end{array}$ & $\begin{array}{l}\text { OR } \\
\text { Time } \\
\text { (mins) }\end{array}$ & $\begin{array}{l}\mathrm{EBL} \\
(\mathrm{ml})\end{array}$ & Complications & $\begin{array}{l}\text { Extent of } \\
\text { Resection }\end{array}$ & $\begin{array}{l}\text { Adjuvant } \\
\text { Therapy }\end{array}$ & $\begin{array}{l}\text { PFS } \\
\text { (mos) }\end{array}$ & $\begin{array}{c}\text { Local } \\
\text { Recurrence }\end{array}$ & $\begin{array}{l}\text { Current } \\
\text { Status }\end{array}$ \\
\hline 1 & $37, \mathrm{M}$ & Chondrosarcoma & $\begin{array}{l}\text { T-12, L-1, } \\
\text { L-2 }\end{array}$ & 776 & 7000 & None & $\begin{array}{l}\text { Wide en bloc } \\
\text { resection }\end{array}$ & None & 30 & None & NED \\
\hline 2 & $23, M$ & Osteoblastoma & C-7 & 232 & 400 & None & $\begin{array}{l}\text { Marginal en bloc } \\
\text { resection }\end{array}$ & None & 26 & None & NED \\
\hline 3 & $57, \mathrm{~F}$ & Chondrosarcoma & T-8, T-9 & 245 & 250 & None & $\begin{array}{l}\text { Marginal en bloc } \\
\text { resection }\end{array}$ & None & 33 & None & NED \\
\hline 4 & $40, F$ & $\begin{array}{c}\text { Metastatic myxoid } \\
\text { liposarcoma }\end{array}$ & $\mathrm{T}-8$ & 490 & 200 & $\begin{array}{l}\text { Hardware failure re- } \\
\text { lated to avascular } \\
\text { necrosis of bone }\end{array}$ & $\begin{array}{l}\text { Marginal en bloc } \\
\text { resection }\end{array}$ & $\begin{array}{l}\text { Radio- \& } \\
\text { chemo- } \\
\text { therapy }\end{array}$ & 33 & None & NED \\
\hline 5 & $62, \mathrm{M}$ & $\begin{array}{l}\text { Metastatic leio- } \\
\text { myosarcoma }\end{array}$ & $\mathrm{T}-11$ & 555 & 500 & None & $\begin{array}{l}\text { Marginal en bloc } \\
\text { resection }\end{array}$ & Radiation & $\begin{array}{l}2 \text { (lung } \\
\text { mets) }\end{array}$ & None & AWD \\
\hline
\end{tabular}

AWD = alive with disease; EBL = estimated blood loss; mets = metastases; NED = no evidence of disease; OR = operating room; PFS = progression-free survival. 

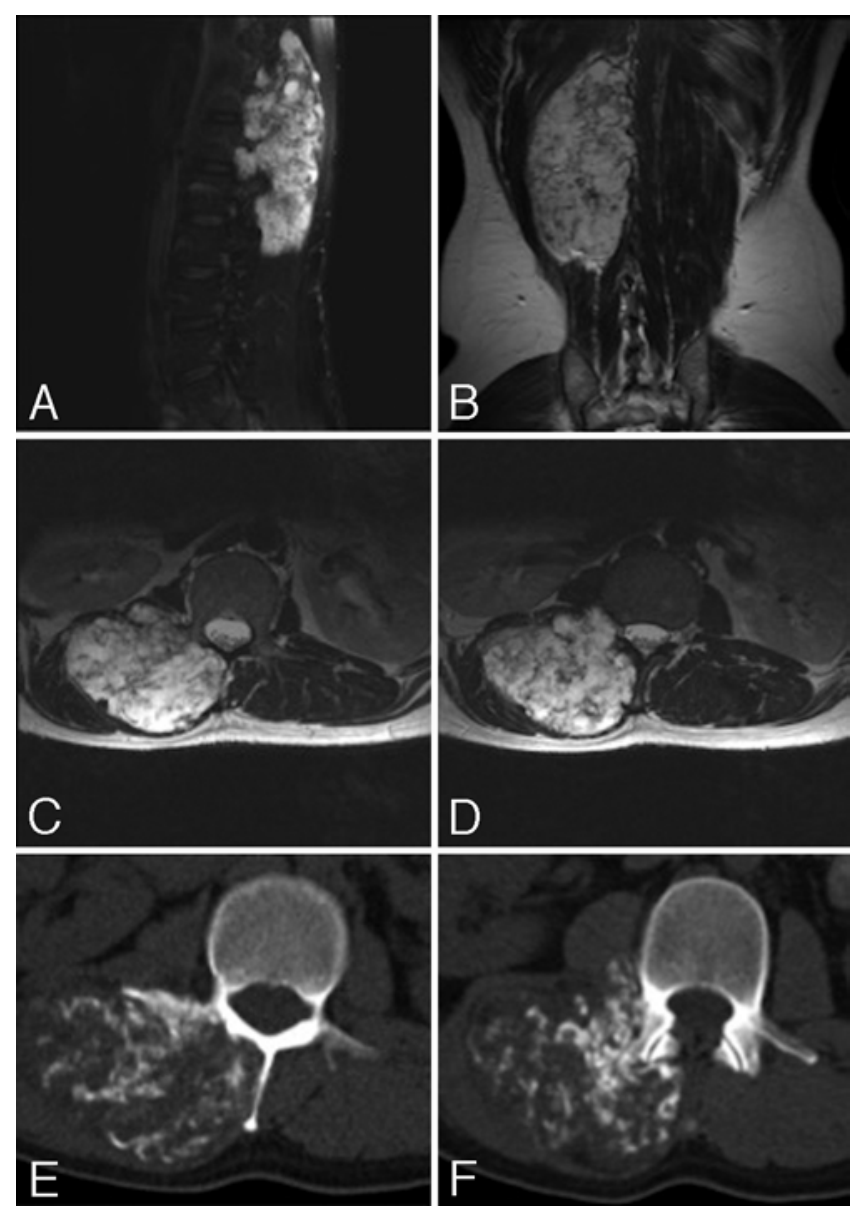

FIG. 4. Case 1. Preoperative sagittal (A), coronal (B), and axial (C and D) MR images and axial CT scans ( $E$ and F) demonstrating a large, calcified, right-sided paraspinal lesion.

of the left lamina of C-7 with the lateral mass. The facet joints were then resected at C6-7 and C7-T1, and the thecal sac was dissected free from the epidural tumor using a Penfield dissector. The pedicle osteotomy was then performed. This resulted in disarticulation and complete en bloc removal of the C-7 spinous process, lamina, lateral mass, and pedicle. The inferior portion of the right C-7 pedicle and vertebral body was then removed using a high-speed drill to ensure that there was no residual tumor. Posterolateral fusion was then completed by connecting rods from C-5 to T-2 bilaterally and decorticating the facet joints. The incision was then closed in layers. Postoperatively, the patient had transient right triceps weakness, which resolved without intervention and imaging demonstrated complete removal of the lesion (Fig. 8).

The final pathological diagnosis was osteoblastoma and, following surgery, the patient recovered well without neurological deficit and experienced improvement in neck pain. He has been monitored for 26 months after surgery with no evidence of disease.

\section{Discussion}

En bloc resection with adequate surgical margins has

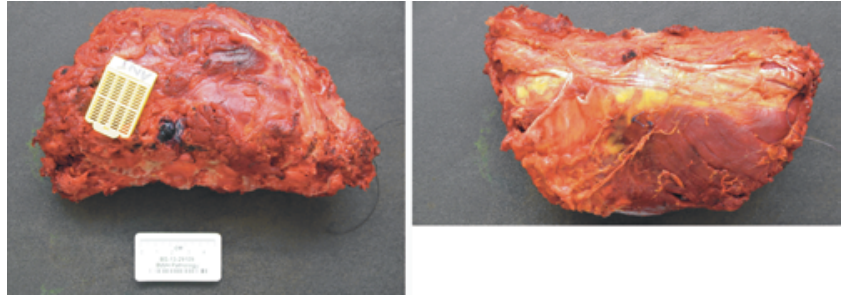

FIG. 5. Case 1. Photographs of a large Grade II chondrosarcoma that was removed en bloc using the COPPER technique.

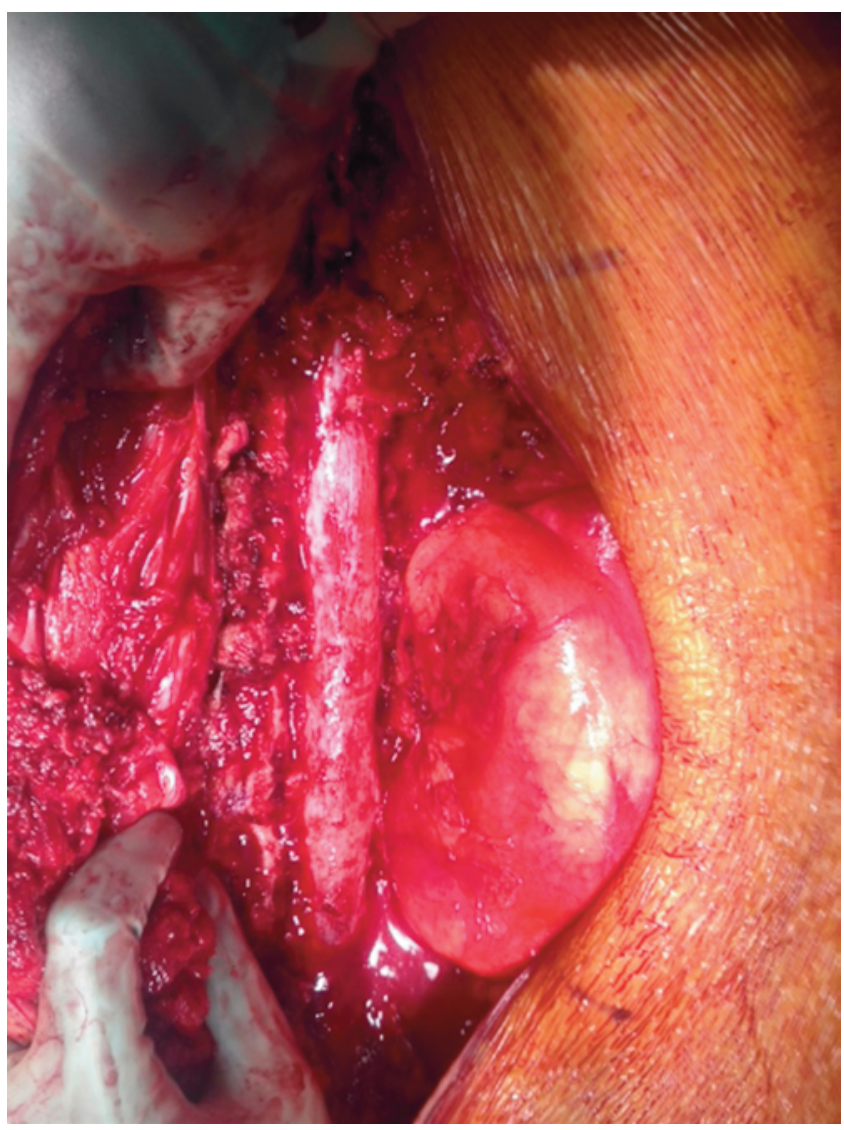

FIG. 6. Case 1. Photograph of the resection cavity following en bloc removal of a large Grade II chondrosarcoma, demonstrating a large muscular defect through which the right kidney and Gerota's fascia herniate posteriorly.

been shown to decrease rates of recurrence and improve progression-free survival for many primary spinal column tumors and isolated metastatic lesions. ${ }^{2,3,6-8,11-13,16,23}$ For benign, locally aggressive tumors such as chordomas, 5 -year survival rates following piecemeal resection range from $50 \%$ to $70 \%$ but may be as high as $100 \%$ with en bloc removal. ${ }^{7,8}$ York et al. retrospectively evaluated $27 \mathrm{pa}-$ tients with sacral chordomas and found that patients who underwent en bloc resection with wide margins had an increased disease-free interval compared with patients who underwent intralesional or marginal excision. ${ }^{24}$ Boriani et al. also examined 52 consecutive patients with chordomas of the mobile spine and found that margin-free en bloc 

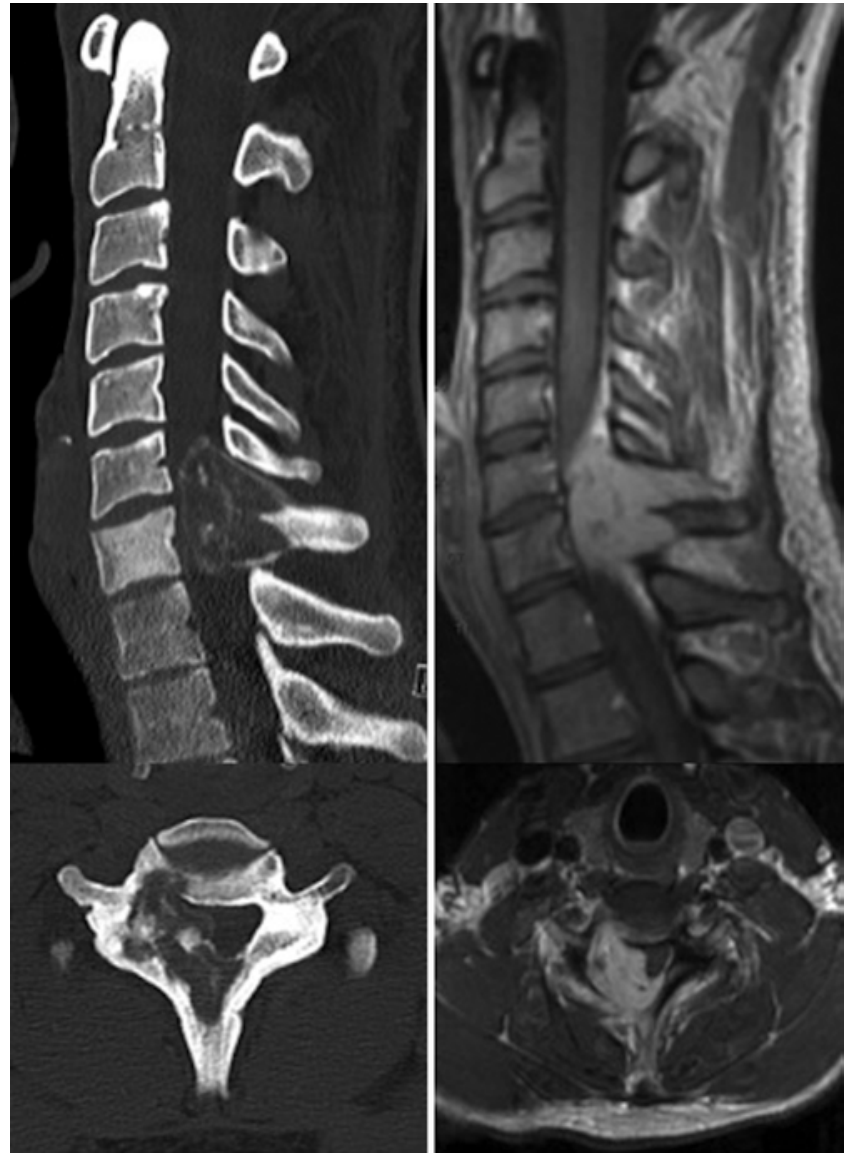

FIG. 7. Case 2. Preoperative sagittal and axial CT scans (left) and sagittal and axial MR images (right) of an expansile C-7 mass with epidural extension, resulting in spinal cord compression.

resection was associated with longer disease-free survival than other treatment protocols. ${ }^{3}$

Patients with malignant spinal tumors are also at high risk of recurrence, and the majority of these patients survive less than 5 years. ${ }^{7}$ However, there is also evidence that en bloc resection may result in delayed recurrence and increased survival. Bergh et al. published a series that included 12 patients with chondrosarcoma of the mobile spine. They discovered that marginal or intralesional removal of the tumor was an adverse prognostic factor for local recurrence when compared with wide resection and also that local recurrence was associated with an increased likelihood of tumor-related death. ${ }^{2}$ Tomita et al. also reviewed 86 patients with primary spinal tumors and found that 5 -year survival for patients with malignant tumors who underwent total en bloc spondylectomy was nearly $70 \% .^{20}$

Although the benefits are well recognized, en bloc resection of spinal tumors is a challenging undertaking due to the difficulty in preserving critical anatomical structures, the requirement for removal of the tumor in one piece, and the need for immediate reconstruction to preserve the mechanical integrity of the spinal column. ${ }^{6-9}$ One systematic review calculated a $36.3 \%$ complication rate for en bloc resection of spinal tumors. ${ }^{8}$ Another retrospective publication reported that patients undergoing en bloc re-

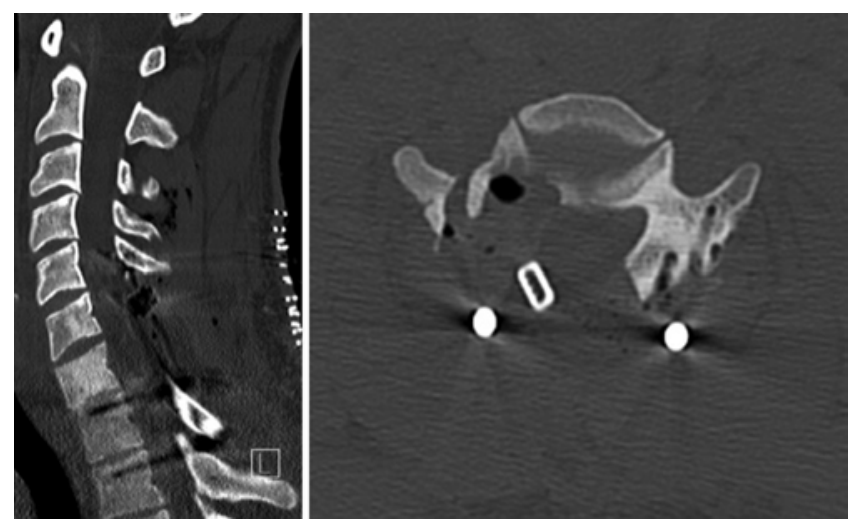

FIG. 8. Case 2. Postoperative sagittal (left) and axial (right) CT scans demonstrating complete removal of the $\mathrm{C}-7$ tumor using the COPPER technique.

section had longer surgeries, higher rates of both early and late surgical complications, and higher rates of revision when compared with patients who underwent piecemeal resection. ${ }^{9}$ Wound complications, excessive blood loss, and neurological injury have also been reported., ${ }^{1,6,10,14}$ The morbidity associated with en bloc resection seems to be even higher in the cervical spine and one group reported a $42 \%$ rate of intraoperative complications-including cervical spinal cord injury-and a $74 \%$ rate of postoperative complications-including death-for intralesional spondylectomy in the cervical spine. ${ }^{22}$

There are a variety of techniques that may be used to accomplish en bloc resection, to some extent depending on the size and location of the tumor. En bloc spondylectomy has been described by Stener ${ }^{17}$ and Roy-Camille et al. ${ }^{15}$ Tomita et al. then popularized the total en bloc spondylectomy in the 1990s..$^{18,19,21}$ Various modifications to these techniques have been described, but it is universally accepted that they are complex, challenging surgical cases with high risk for complications even in experienced hands. Most surgeons find the high rates of complication associated with en bloc spondylectomy to be acceptable as long as they allow the patient to enjoy a better oncological prognosis. However, we have found that patients with posterolateral spinal tumors may be amenable to less extensive surgery while still achieving the oncological goals of resection.

In this paper, we provide a technical description and overview of our experience with the COPPER technique for en bloc resection of low-grade malignant and aggressive benign tumors involving the posterolateral spinal column. By creating a hemilaminectomy on the unaffected side and undercutting the spinous process, the contralateral pedicle can be identified and an osteotomy can be performed through the pedicle base to disarticulate the pedicle, superior and inferior articulating processes, lamina, spinous process, and surrounding soft tissue. In our series of 5 patients who underwent this procedure for the resection of various tumors involving the spinal column (including chondrosarcoma, osteoblastoma, liposarcoma, and leiomyosarcoma), we found that it was possible to obtain an oncological resection without significant complications. Since anterior column reconstruction was not needed, we 
were able to reduce the amount of instrumentation, and, as a result, only 1 patient had a hardware complication related to avascular necrosis of the surrounding bone from high-dose radiation. Also, none of the patients had local recurrence of disease, suggesting that this procedure may be sufficient for local tumor control.

\section{Conclusions}

The COPPER technique allows for oncological resection of lateral and posterolateral tumors of the spinal column by performing a zone-specific en bloc resection. Our experience suggests that this procedure may be used to perform en bloc resection while avoiding the morbidity associated with more traditional approaches and obviating the need for anterior column reconstruction. Although it is frequently possible to obtain wide surgical margins, a marginal resection may be obtained in cases with epidural extension of the tumor as long as the tumor capsule is preserved during its separation from the dura.

\section{References}

1. Amendola L, Cappuccio M, De Iure F, Bandiera S, Gasbarrini A, Boriani S: En bloc resections for primary spinal tumors in 20 years of experience: effectiveness and safety. Spine J 14:2608-2617, 2014

2. Bergh P, Gunterberg B, Meis-Kindblom JM, Kindblom LG: Prognostic factors and outcome of pelvic, sacral, and spinal chondrosarcomas: a center-based study of 69 cases. Cancer 91:1201-1212, 2001

3. Boriani S, Bandiera S, Biagini R, Bacchini P, Boriani L, Cappuccio M, et al: Chordoma of the mobile spine: fifty years of experience. Spine (Phila Pa 1976) 31:493-503, 2006

4. Boriani S, Bandiera S, Donthineni R, Amendola L, Cappuccio $\mathrm{M}$, De Iure F, et al: Morbidity of en bloc resections in the spine. Eur Spine J 19:231-241, 2010

5. Boriani S, Weinstein JN, Biagini R: Primary bone tumors of the spine. Terminology and surgical staging. Spine (Phila Pa 1976) 22:1036-1044, 1997

6. Charest-Morin R, Dea N, Fisher CG: Health-related quality of life after spine surgery for primary bone tumour. Curr Treat Options Oncol 17:9, 2016

7. Chi JH, Sciubba DM, Rhines LD, Gokaslan ZL: Surgery for primary vertebral tumors: en bloc versus intralesional resection. Neurosurg Clin N Am 19:111-117, 2008

8. Cloyd JM, Acosta FL Jr, Polley MY, Ames CP: En bloc resection for primary and metastatic tumors of the spine: a systematic review of the literature. Neurosurgery 67:435-445, 2010

9. Elder BD, Sankey EW, Goodwin CR, Kosztowski TA, Lo SF, Bydon A, et al: Surgical outcomes in patients with high spinal instability neoplasm score secondary to spinal giant cell tumors. Global Spine J 6:21-28, 2016

10. Fisher CG, Keynan O, Boyd MC, Dvorak MF: The surgical management of primary tumors of the spine: initial results of an ongoing prospective cohort study. Spine (Phila Pa 1976) 30:1899-1908, 2005

11. Fourney DR, Rhines LD, Hentschel SJ, Skibber JM, Wolinsky JP, Weber KL, et al: En bloc resection of primary sacral tumors: classification of surgical approaches and outcome. J Neurosurg Spine 3:111-122, 2005

12. Hasegawa K, Homma T, Hirano T, Ogose A, Hotta T, Yajiri Y, et al: Margin-free spondylectomy for extended malignant spine tumors: surgical technique and outcome of 13 cases. Spine (Phila Pa 1976) 32:142-148, 2007

13. Hsieh PC, Xu R, Sciubba DM, McGirt MJ, Nelson C, Witham TF, et al: Long-term clinical outcomes following en bloc resections for sacral chordomas and chondrosarcomas: a series of twenty consecutive patients. Spine (Phila Pa 1976) 34:2233-2239, 2009

14. Mazel C, Owona P, Cogan A, Balabaud L, Grunenwald D: Long-term quality of life after en-bloc vertebrectomy: 25 patients followed up for 9 years. Orthop Traumatol Surg Res 100:119-126, 2014

15. Roy-Camille R, Saillant G, Bisserié M, Judet T, Hautefort E, Mamoudy P: [Total excision of thoracic vertebrae (author's transl).] Rev Chir Orthop Repar Appar Mot 67:421-430, $1981(\mathrm{Fr})$

16. Stener B: Complete removal of vertebrae for extirpation of tumors. A 20-year experience. Clin Orthop Relat Res (245):72-82, 1989

17. Stener B: Total spondylectomy in chondrosarcoma arising from the seventh thoracic vertebra. J Bone Joint Surg Br $\mathbf{5 3 : 2 8 8 - 2 9 5 , 1 9 7 1}$

18. Tomita K, Kawahara N, Baba H, Tsuchiya H, Fujita T, Toribatake Y: Total en bloc spondylectomy. A new surgical technique for primary malignant vertebral tumors. Spine (Phila Pa 1976) 22:324-333, 1997

19. Tomita K, Kawahara N, Baba H, Tsuchiya H, Nagata S, Toribatake Y: Total en bloc spondylectomy for solitary spinal metastases. Int Orthop 18:291-298, 1994

20. Tomita K, Kawahara N, Murakami H, Demura S: Total en bloc spondylectomy for spinal tumors: improvement of the technique and its associated basic background. J Orthop Sci 11:3-12, 2006

21. Tomita K, Toribatake Y, Kawahara N, Ohnari H, Kose H: Total en bloc spondylectomy and circumspinal decompression for solitary spinal metastasis. Paraplegia 32:36-46, 1994

22. Wei F, Liu Z, Liu X, Jiang L, Dang G, Passias PG, et al: An approach to primary tumors of the upper cervical spine with spondylectomy using a combined approach: our experience with 19 cases. Spine (Phila Pa 1976) [epub ahead of print], 2015

23. Yamazaki T, McLoughlin GS, Patel S, Rhines LD, Fourney DR: Feasibility and safety of en bloc resection for primary spine tumors: a systematic review by the Spine Oncology Study Group. Spine (Phila Pa 1976) 34 (22 Suppl):S31-S38, 2009

24. York JE, Kaczaraj A, Abi-Said D, Fuller GN, Skibber JM, Janjan NA, et al: Sacral chordoma: 40-year experience at a major cancer center. Neurosurgery 44:74-80, 1999

\section{Disclosures}

Dr. Chi reports that he is a consultant for K2M.

\section{Author Contributions}

Conception and design: Chi, Vasudeva, Ropper. Acquisition of data: Vasudeva, Ropper. Analysis and interpretation of data: Vasudeva. Drafting the article: Vasudeva. Critically revising the article: Chi, Vasudeva, Ropper, Wu. Reviewed submitted version of manuscript: all authors. Approved the final version of the manuscript on behalf of all authors: Chi. Study supervision: Chi. Illustration of figures: Rodriguez.

\section{Supplemental Information \\ Videos}

Video 1. https://vimeo.com/179759374.

\section{Correspondence}

John H. Chi, Department of Neurosurgery, Brigham and Women's Hospital, Harvard Medical School, 75 Francis St., Boston, MA 02115. email: jchi@partners.org. 